\title{
Exertional rhabdomyolysis in a patient with calcium adenosine triphosphatase deficiency
}

\author{
P J E Poels, R A Wevers, J P Braakhekke, A A G M Benders, J H Veerkamp, \\ E M G Joosten
}

\begin{abstract}
A patient with exertional rhabdomyolysis and continuously elevated serum creatine kinase (CK) was investigated. The known causes of recurrent attacks of rhabdomyolysis were ruled out by appropriate histochemical and biochemical investigations. During ischaemic exercise tests an abnormal $\mathrm{K}^{+}$-efflux from exercising muscles was observed. The patient was found to have a deficiency of muscular $\mathrm{Ca}^{2}+$-ATPase. Dantrolene sodium therapy gave relief of muscle symptoms and improved the exercise tolerance. Both the CK level and the $\mathrm{K}^{+}$efflux in ischaemic forearm testing became normal on this therapy.
\end{abstract}

(F Neurol Neurosurg Psychiatry 1993;56:823-826)

Recurrent attacks of exertional rhabdomyolysis can develop from several enzyme defects of glyco(geno)lysis or lipid metabolism. ${ }^{1}$ Rhabdomyolysis has not been associated with $\mathrm{Ca}^{2+}$-adenosine triphosphatase $\left(\mathrm{Ca}^{2+}\right.$ ATPase) deficiency. This rare disorder of muscle function was first described by Brody in $1969 . .^{2}$ In recent years three reports have been published, describing patients with deficiency of sarcoplasmic reticulum-ATPase..$^{3-5}$ Exercise-induced muscle contractures and impaired relaxation of exercising muscles belong to the main clinical symptoms. The deficiency causes a reduced uptake of $\mathrm{Ca}^{2+}$ in sarcoplasmic reticulum. Several studies have shown the importance of calcium ions in the contraction-relaxation cycle of striated muscles. ${ }^{2}$

We describe a patient with exertional myalgia and recurrent rhabdomyolysis. We tested this patient with dantrolene sodium since this drug has been suggested to be useful in the treatment of exertional myalgia and recurrent rhabdomyolysis. ${ }^{6-8}$ Dantrolene sodium acts primarily by decreasing the sarcoplasmic reticulum calcium release and depresses the trigger mechanism for the excitationcontraction coupling, which is supposed to play a key role in the development of muscle pain and stiffness. ${ }^{69}$ The effect of dantrolene sodium on muscle symptoms and on ischaemic exercise tests is discussed.

\section{Case report}

A 38 year old male presented with exertional myalgia and postexercise muscle weakness. These symptoms of exercise-intolerance started during the first decade of life. His skeletal muscles became stiff and painful 5 minutes after the start of moderate isometric exercise. He had many episodes of pigmenturia, especially after sport. He was not able to play a volleyball match to the end because of stiffening of the exercised muscles. The muscle symptoms then lasted for at least 12 hours. He frequently experienced "cramping" in the calf muscles. Walking and cycling caused no problems. When chewing firmly, the masticatory muscles became stiff and the relaxation was impaired. The patient did not experience a second wind phenomenon. The family history was noncontributory. Physical examination revealed no abnormalities. There was no muscle atrophy and no muscle weakness. Grip and percussion myotonia were absent. Laboratory studies showed a continuously elevated serum CK ranging from 500 to 1500 IU/L (normal range 15-91). After sport, serum CK rose to $11000 \mathrm{IU} / \mathrm{L}$. A normal biochemical and haematological profile was obtained. Blood lactate level was within the normal range and showed a fourfold rise in response to exercise. EMG showed normal conduction velocities. No myotonic discharges were observed in intrinsic hand muscles, quadriceps or tibialis anterior.

Because of recurrent attacks of exertional myalgia the patient was treated with dantrolene sodium. The dose was slowly built up to $150 \mathrm{mg}$ a day and continued for six months. Exercise-tolerance improved and the patient was again able to participate in sport without muscle problems. When dantrolene sodium was discontinued for two months, all muscle complaints returned. Symptoms disappeared again when the medication was resumed. In the period without dantrolene sodium, CK level was determined twice and clearly elevated to 1125 and $1429 \mathrm{IU} / \mathrm{L}$ respectively. During dantrolene sodium treatment $\mathrm{CK}$ level was determined three times and had decreased to 105, 185, and $115 \mathrm{IU} / \mathrm{L}$ respectively.

Special studies

A muscle biopsy from the vastus medialis was 
processed according to standard procedures for histochemistry and electronmicroscopy. Carnitine palmitoyltransferase I and II activities were measured in leukocytes and in muscle homogenate with the exchange assay. ${ }^{10}$ The activity of alpha-glucosidase was determined in leukocytes and in muscle. Concentrations of free and esterified carnitine were determined in blood and muscle tissue. ${ }^{11}$ An extensive biochemical study of mitochondrial metabolism and enzymes was performed according to standard procedures. ${ }^{12}$

In muscle homogenates $(1 \% \mathrm{w} / \mathrm{v})$ the $\mathrm{Ca}^{2+}$ dependent $\mathrm{Mg}^{2+}$-ATPase of sacroplasmic reticulum was investigated by measurement of the $\mathrm{Ca}^{2+}$-dependent 3-0-methylfluorescein phosphatase (3-0-MFPase) activity according to the method described by Everts et al. ${ }^{13}$ The $\mathrm{Na}^{+} / \mathrm{K}^{+}$-ATPase activity was estimated from the $\mathrm{K}^{+}$-dependent 3-0-MFPase activity according to Norgaard et al. ${ }^{14}$

To exclude a glyco(geno)lytic enzyme defect glycolytic enzymes in erythrocytes were determined and ischaemic forearm tests were carried out under standardised conditions. ${ }^{15}$ Two ischaemic forearm tests were performed during dantrolene therapy and two tests without medication. In the blood samples taken before and immediately after exercise, changes in plasma electrolyte levels were studied. ${ }^{16}$

\section{Results}

Laboratory investigations

Normal values were found for carnitine palmitoyltransferase I and II in leukocytes and in muscle homogenate. In red blood

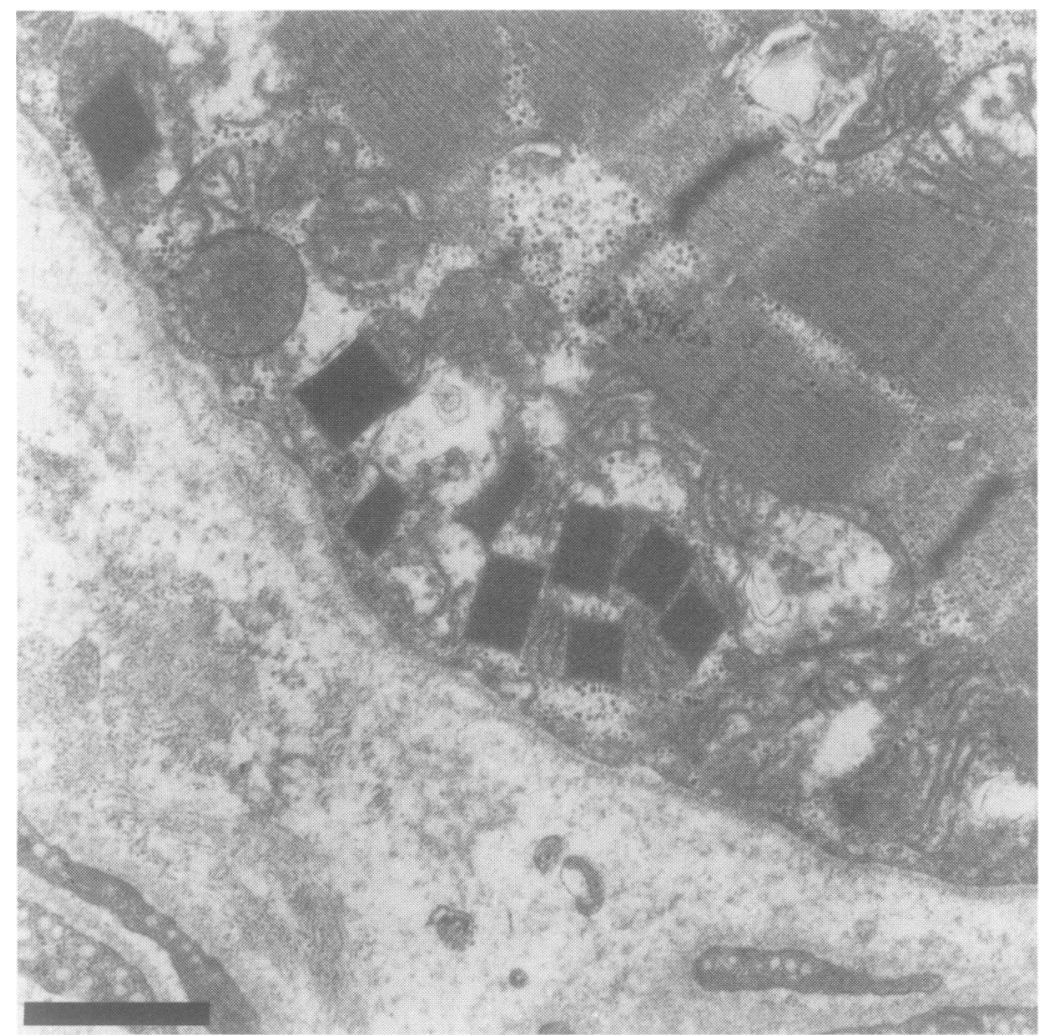

Figure 1 Electron microscopy. A number of subsarcolemmal mitochondria which are swollen and contain crystalline inclusions. Bar $=1 \mu \mathrm{m}$. cells there was no deficiency of glycolytic enzymes. The activity of alpha-glucosidase in the leukocytes and in the muscle was normal. Free and esterified carnitine in serum and muscle were normal. Muscle homogenate showed a normal oxidation rate of $\left[1-{ }^{14} \mathrm{C}\right]$ pyruvate and $\left[\mathrm{U}-{ }^{14} \mathrm{C}\right]$ malate, no defect in ATP metabolism and normal activities of mitochondrial enzymes.

The $\mathrm{Ca}^{2+}$-dependent 3-O-MFPase activity in muscle was significantly reduced to 589 $\mathrm{pmol} /$ minute per $\mathrm{mg}$ protein compared with the control value of $1134 \pm 227(n=14)$. A normal activity was found for $\mathrm{K}^{+}$-dependent 3-0-MFPase of $414 \mathrm{pmol} / \mathrm{minutes}$ per $\mathrm{mg}$ protein versus $382 \pm 73(n=14)$.

\section{MORPHOLOGICAL STUDIES}

Histological studies of the muscle biopsy showed $19 \%$ central nuclei (normal $<3 \%$ ), some necrotic fibres and an increased variation of fibre diameter. Myophosphorylase and myoadenylate deaminase staining reactions were positive. A trichrome stain was negative and no ragged red fibres were seen. Histochemical study revealed a slight amount of subsarcolemmal PAS-positive material. Electronmicroscopy showed muscle fibres with an increased amount of glycogene. A substantial number of subsarcolemmal mitochondria were swollen and contained crystals (fig 1). The structures of the triad and the tubular elements of sarcoplasmic reticulum were normal.

\section{ISCHAEMIC FOREARM TESTS}

All four ischaemic exercise tests showed a normal rise of venous lactate and ammonia. During the two forearm tests without medication an excessive increase of serum potassium was found immediately after ischaemic exercise (fig 2). The $\mathrm{K}^{+}$-efflux was normal in the two ischaemic forearm tests at dantrolene sodium treatment.

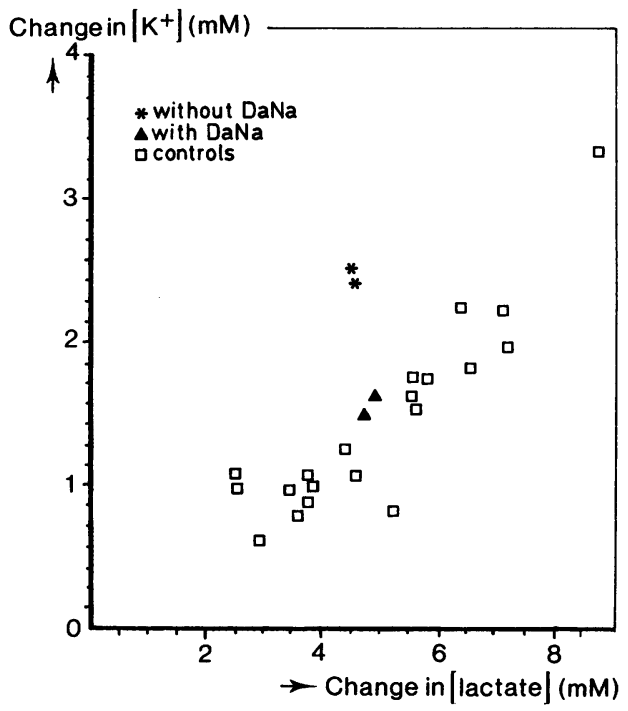

Figure 2 Abnormal increase of serum potassium in relation to the concentration lactate during the ischaemic forearm test. During dantrolene sodium ( $\mathrm{DaNa}$ ) medication the $\mathrm{K}^{+}$release was in the normal range of the controls. 


\section{Discussion}

$\mathrm{Ca}^{2+}$-ATPase deficiency is a rare inborn error of metabolism. Its clinical presentation is not specific. Impaired muscle relaxation, muscle contractures and exertional muscle pain are the main features. Hitherto rhabdomyolysis has not been associated with $\mathrm{Ca}^{2+}$-ATPase deficiency. The diagnosis is established by measuring the microsomal $\mathrm{Ca}^{2+}$-uptake, ${ }^{24}$ quantifying the activity of $\mathrm{Ca}^{2+}$-ATPase in muscle homogenate ${ }^{14}$ or by immunochemical tests. ${ }^{417}$

$\mathrm{K}^{+}$-efflux from exercising muscle is considered a normal physiological phenomenon. ${ }^{16} 18$ The efflux of $\mathrm{K}^{+}$in the venous return blood of the exercising forearm was excessive in this patient. The normal values found for $\mathrm{Na}^{+} / \mathrm{K}^{+}$-ATPase activity excluded a reuptake disorder of $\mathrm{K}^{+}$as cause of its excessive efflux. The $\mathrm{K}^{+}$efflux may be explained by the effect of a disturbed $\mathrm{Ca}^{2+}$-homeostasis on the $\mathrm{Ca}^{2+}$ activated $\mathrm{K}^{+}$-channels. ${ }^{10}$ This hypothesis is supported by the strongly reduced activity of sarcoplasmic reticulum $\mathrm{Ca}^{2+}-\mathrm{ATPase}$ that was found in the muscle homogenate of this patient.

Electron microscopic findings showed normal structures of triad and tubular elements of sarcoplasmic reticulum, but swollen mitochondria with crystals. Crystalline mitochondrial inclusions are often seen under pathological conditions concerned with energy metabolism. These crystals may be considered as a secondary effect of the disturbed calcium homeostasis on mitochondria.

To date four case reports of $\mathrm{Ca}^{2+}$-ATPase deficiency have been published. The first case described by Brody in 1969 had considerable problems with relaxation of exercising muscles. ${ }^{2}$ Karpati et al described 4 male patients with similar complaints about exertional muscle stiffness and contractures. CK level in only one of them was slightly elevated. The mode of inheritance in this family was autosomal recessive. ${ }^{4}$ Danon et al described four family members with impaired muscle relaxation and an autosomal dominant mode of inheritance. ${ }^{3}$ Taylor et al reported a $\mathrm{Ca}^{2+}$ ATPase deficiency in a patient with an exertional muscle pain syndrome. ${ }^{5}$ Our patient had exercise-induced myalgia, recurrent attacks of myoglobinuria and a constantly elevated CK level. Relaxation of muscles was sometimes difficult but not the patient's main problem.

The clinical picture of muscle relaxation problems in these patients resembles myotonic dystrophy or myotonia congenita. However, these patients do not demonstrate clinical or electrical myotonia. Their delayed muscle relaxation is painless in contrast to muscle contractions in myotonia syndromes. Conversely, $\mathrm{Ca}^{2+}$-ATPase deficiency shows a resemblance with McArdle's disease and phosphofructokinase deficiency because of the electromyographical silence during relaxation.

The main difference between our patient and the previous cases $^{2-5}$ is the exertional recurrent rhabdomyolysis, confirmed by ele- vated $\mathrm{CK}$ levels. For muscle relaxation to occur, $\mathrm{Ca}^{2+}$-ions released into cytosol during contraction, must be taken up into the sarcoplasmic reticulum lumen through activity of $\mathrm{Ca}^{2+}$-ATPase located in the sarcoplasmic reticulum membrane. The partial deficiency of this enzyme may explain the main presenting symptoms in this disease: problems in relaxation of muscles, aggravated by exercise, muscle stiffness and exertional myalgia. When sarcoplasmic reticulum $\mathrm{Ca}^{2+}$-uptake cannot keep pace with $\mathrm{Ca}^{2+}$-release, then an accumulation of $\mathrm{Ca}^{2+}$ in muscle cytosol will occur. If at a critical level, a sustained elevation in cytosolic $\mathrm{Ca}^{2+}$-concentration will be damaging to muscle cells, and will result in muscle cell necrosis and pigmenturia. Myoglobinuria has not yet been associated with $\mathrm{Ca}^{2+}$-ATPase deficiency, which may be attributed to the very small number of case reports up till now. The degree of deficiency of $\mathrm{Ca}^{2+}$-ATPase may be important for the development of muscle damage. Verapamil and dantrolene sodium are the therapeutic drugs that have been successfully used in the treatment of exertional myalgia. In the patient described by Taylor dantrolene sodium reduced the pain, but produced unacceptable weakness. ${ }^{5}$ Verapamil proved to be effective. The therapeutic use of dantrolene sodium in preventing muscle necrosis has been reported before in animal experiments. ${ }^{6}$ Its beneficial effect in humans has also been reported by us and others in treating exertional myalgia and preventing recurrent attacks of rhabdomyolysis. ${ }^{8917}$ In our patient dantrolene sodium also had a positive effect upon exercise tolerance and muscle complaints; moreover, CK level and plasma potassium efflux from ischaemic exercising muscles became normal.

Recurrent rhabdomyolysis in metabolic myopathies is mainly precipitated by exercise. The number of recognised metabolic defects has increased in the past two decades, but in about half of the cases the biochemical cause of recurrent rhabdomyolysis remains unknown. ${ }^{1}$ We suggest that account $\mathrm{Ca}^{2+}$ ATPase deficiency as a metabolic cause of recurrent exertional rhabdomyolysis should be considered.

The authors thank Dr Th M N Breuer, for his cooperation and Mrs G Steenbergen for her assistance in this study.

This investigation is part of the research programme "Disorders of the Neuromuscular System" at the University of Nijmegen.

1 Tonin P, Lewis P, Serveidi S, DiMauro S. Metabolic causes of myoglobinuria. Ann Neur 1990;27:181-5.

2 Brody IA. Muscle contracture induced by exercise. A syndrome attributable to decreased relaxing factor. The New Eng ₹ Med 1969;281:187-92.

3 Danon MJ, Karpati G, Charuk J, Holland P. Sarcoplasmic reticulum adenosine triphosphatase defiSarcoplasic reticulum adenosine triphosphatase defiNeurology 1988;38:813-15.

4 Karpati G, Charuk J, Carpenter S, Jablecki C, Holland P. Myopathy caused by a deficiency of $\mathrm{Ca}^{2+}$-adenosine Myopathy caused by a deficiency of Ca ${ }^{2+}$-adenosine triphosphate in sarcoplasmic retic

5 Taylor DJ, Brosnan MJ, Arnold DL, et al. $\mathrm{Ca}^{2+}-\mathrm{ATPase}$ deficiency in a patient with an exertional muscle pain deficiency in a patient with an exertional muscle pain syndrome. I Neurol Neurosurg Psychiatry 1988;51: 1425-33.

6 Amelink GJ. Exercise induced muscle damage. Thesis 1990, Utrecht, The Netherlands. 
7 Bertorini T, Palmieri G, Bhattacharya G. Beneficial effects of dantrolene sodium in exercise-induced muscle pains: calcium mediated? Lancet 1982;i:616-7.

8 Haverkort-Poels PJE, Joosten EMG, Ruitenbeek W. Prevention of recurrent thabdomyolysis by dantrolene sodium. Muscle Nerve 1987;10:45-6.

9 Lopez JR. Dantrolene sodium is able to reduce the resting calcium ion intracellular concentration in muscle from humans with malignant hyperthermia. Muscle Nerve 1987;10:77-9.

10 Scholte HR, Jennekens FGI, Bouvy JJBJ. Carnitine palmitoyltransferase II deficiency with normal carnitine palmitoyltransferase I in skeletal muscle and leukocytes. f Neurol Sci 1979;40:39-51.

11 Parvin R, Pande SV. Microdetermination of (-)carnitine and carnitine acetyltransferase activity. Anal Biochem 1977;79:190-201.

12 Trijbels JMF, Sengers RCA, Ruitenbeek W, et al. Disorders of mitochondrial chain: clinical manifestations and diagnostic approach. Eur $f$ Paediatr 1988;148:92-7.
13 Everts ME, Andersen JP, Clausen $T$, Hansen $O$. Quantitative determination of $\mathrm{Ca}^{2+}$-dependent $\mathrm{Mg}^{2+}$ ATPase from sarcoplasmic reticulum in muscle biopsies. Bioch F 1989;260:443-8.

14 Nørgaard A, Kjeldsen $\mathrm{K}$, Hansen $\mathrm{O}$. $\mathrm{Na}^{+}+\mathrm{K}^{+}$-ATPase activity of crude homogenates of rat skeletal muscle as estimated from their $\mathrm{K}^{+}$-dependent 3-0-methylfluorescein phosphatase activity. Biochimica et Biophysica Acta 1984;770:203-209.

15 Sinkeler SP, Wevers RA, Joosten EMG. Improvement of screening in exertional myalgia with a standardized screening in exertional myalgia with a standardized
ischemic fore arm test. Muscle Nerve 1986;9:731-7.

16 Wevers RA, Joosten EMG, Van de Biezenbos JBM, Theeuwes AGM, Veerkamp JH. Excessive plasma $\mathrm{K}^{+}$ increase after ischemic exercise in myotonic muscular dystrophy, Muscle Nerve 1990;3:27-32.

17 Brumback RA, Gerst JW. A reply. Muscle Nerve 1984;7:593-4.

18 Sjøgaard G. Role of exercise-induced potassium fluxes underlying muscle fatigue: a brief review. Can $\mathcal{F}$ Physiol Pharmacol 1991;69:238-45. 